\title{
Repair of symptomatic neoaortic aneurysm after third-stage palliation for hypoplastic left heart syndrome
}

\author{
Jeffrey H. Shuhaiber, MD, ${ }^{a}$ Vinu Patel, MD, ${ }^{b}$ Tarek Husayni, MD, ${ }^{c}$ Chawki El-Zein, MD, ${ }^{c}$ Mary J. Barth, MD, ${ }^{c}$ \\ and Michel N. Ilbawi, MD, ${ }^{\mathrm{c}}$ Chicago and Oak Lawn, III
}

Supplemental material is
available online.

Clinical Summary

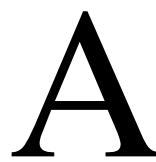

41/2-year-old child with hypoplastic left heart syndrome had successfully undergone stage 3 surgical palliation. Dilatation of the neoaorta $(28 \mathrm{~mm})$ was first noticed 24 months after a stage 1 Norwood procedure. Progressive enlargement was documented by serial echocardiographic evaluation. At pre-Fontan cardiac catheterization the neoaorta was $32 \mathrm{~mm}$ at the mid-ascending level and the pulmonary valve (neoaortic valve) was $27 \mathrm{~mm}$ with mild-to-moderate insufficiency. Four months after the extracardiac Fontan procedure the child had syncopal episodes during exercise associated with pallor and weakness. Thorough neurologic evaluation was unrevealing. Holter monitor recordings and electrophysiologic studies were essentially negative except for mild sick sinus syndrome with no inducible arrhythmias. Hematologic work-up was within normal limits. Cardiac catheterization showed complete occlusion of the left pulmonary artery and interval growth of the aneurysm to $55 \mathrm{~mm}$ (23 mm increase) in diameter over 20 months (Figure 1, A and $B$ ). Follow-up cardiac catheterization after 1 month of warfarin sodium (Coumadin) and aspirin therapy revealed complete recanalization of the occluded pulmonary artery yet persistent compression by the neoaortic aneurysm. Thrombophilia work-up was within normal limits. The patient underwent successful stent placement of the left pulmonary artery to optimize pulmonary flow. Despite stenting, he continued to have symptoms. Therefore, in the presence of a growing symptomatic neoaortic aneurysm, a decision for definitive surgical management was made.

Cardiopulmonary bypass was instituted with aortic arch cannulation. A continuous infusion of cold blood cardioplegic solution was given through an angiocatheter inserted in the native ascend-

From Loyola University Stritch School of Medicine, ${ }^{a}$ Chicago, Christ Medical Center, Department of Pathology, ${ }^{\mathrm{b}}$ and The Heart Institute for Children, Hope Children Hospital, ${ }^{\mathrm{c}}$ Oak Lawn, Ill.

Received for publication June 30, 2005; revisions received Sept 28, 2005; accepted for publication Sept 29, 2005.

Address for reprints: Jeffrey H. Shuhaiber, MD, Department of Surgery, Loyola University Stritch School of Medicine, 614-G Laflin, Chicago, IL 60612 (E-mail: jeffrey01@mac.com).

J Thorac Cardiovasc Surg 2006;131:478-9

$0022-5223 / \$ 32.00$

Copyright $\odot 2006$ by The American Association for Thoracic Surgery doi:10.1016/j.jtcvs.2005.09.047

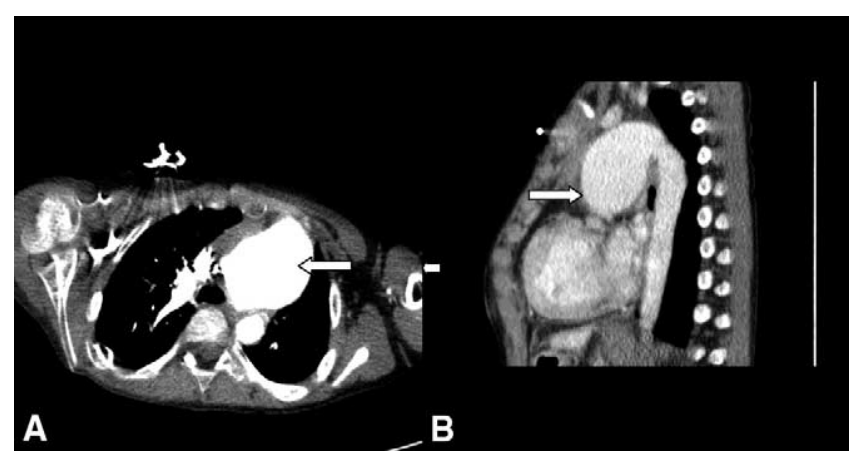

Figure 1. A and B, Computed tomographic frames of the chest with intravenous contrast demarcating a large neoaortic aneurysm (arrows).

ing aorta after crossclamping. A right atrial vent was placed for decompression. Systemic perfusion was interrupted while, at $20^{\circ} \mathrm{C}$, the arterial cannula was advanced to the innominate artery to maintain continuous antegrade cerebral perfusion at $20 \mathrm{~mL} \cdot \mathrm{kg} \cdot \mathrm{min}$. The dilated neoaorta was transected at the sinotubular junction proximally and at the arch distally. The ostium of the native aorta was detached with a button of aortic tissue excised. The aorta was reconstructed distally first, with anastomosis of a 24-mm polytetrafluoroethylene (PTFE) graft (Gore-Tex; W. L. Gore \& Associates, Inc, Flagstaff, Ariz). Systemic circulation was then reestablished. The proximal anastomosis at the level of the sinotubular junction was completed during the rewarming phase. The button of aortic wall was reattached to the PTFE graft. The pulmonic valve (neoaortic) annulus was downsized by an anterior external application of a 3-mm strip of $0.6 \mathrm{~mm}$ PTFE. This downsized aortic annulus, from 28 to $24 \mathrm{~mm}$, was observed at 3 months postoperatively (Figure E1, $A$ and $B$ ). The patient's postoperative course was unremarkable. He was discharged home on postoperative day 7. Postoperative echocardiograms at 2 months revealed a normaldiameter ascending aorta $(24 \mathrm{~mm})$ and mild pulmonic valve insufficiency.

Gross examination of the resected aneurysm showed fragments of vessel wall between 0.2 to $0.3 \mathrm{~cm}$ with glistening intimal surfaces and mild focal sclerosis.

Microscopic examination of tissues stained with hematoxylin and eosin, elastic, trichrome, and alcian blue stains revealed portions of aortic and graft wall including suture remnants. There was no evidence of inflammation, pseudoaneurysm formation, or dissection. Disruption of numerous elastic laminae with parallel arrangement and foci of fibrointimal proliferation were visualized in the vicinity of the pericardial patch-native great vessel anastomo- 

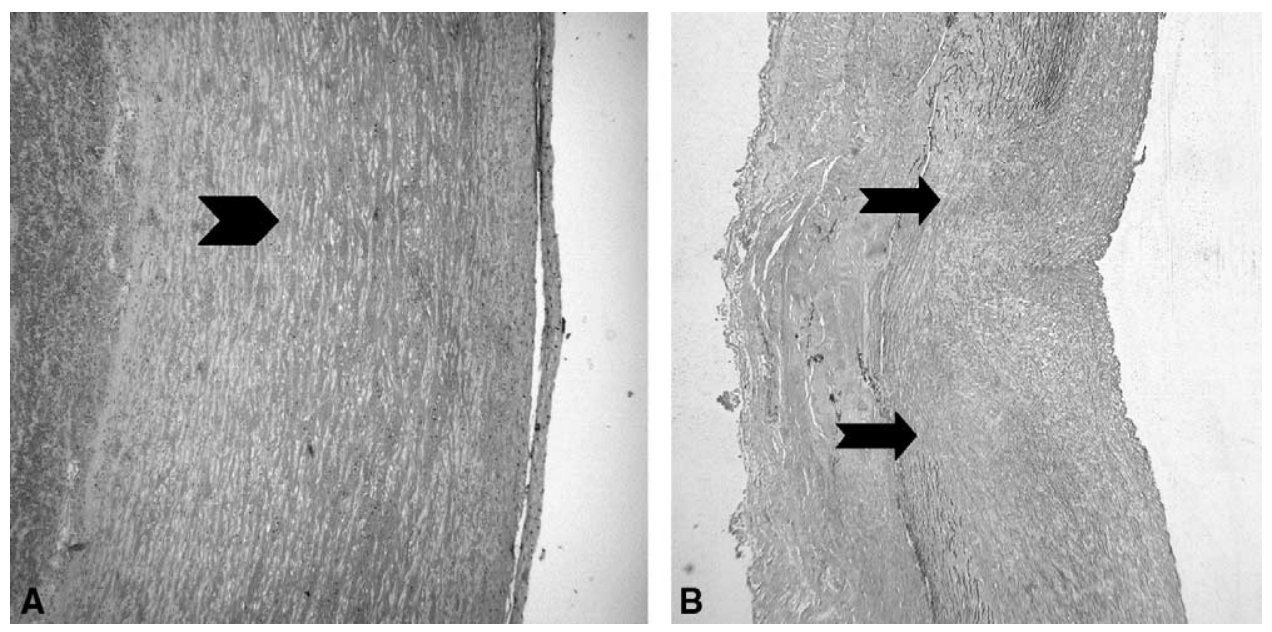

Figure 2. A, Alcian blue stain showing cystic medial degenerative changes. B, Neoaorta and pericardial graft showing numerous elastic laminae with parallel arrangement and foci of fibrointimal proliferation $(\times 400)$. Some elastic laminae separated by pale myxoid material with foci of cystic medial degeneration.

sis. Some elastic laminae separated by pale myxoid material suggested foci of cystic medial degeneration (Figure 2, $A$ and $B$ ).

\section{Discussion}

Various problems not infrequently seen in patients after stage 1 surgery include distortion of the central pulmonary artery and pulmonary valve incompetence. ${ }^{1}$ However, aneurysmal dilation of the neoaorta is rare.

There has been one report of aneurysm formation of the neoaorta. $^{2}$ The authors suggested that both neoaortic regurgitation and aneurysm formation were probably related to the homograft patch material used, the pulmonary valve, and its sinotubular component, or a combination of these factors. Although in our case we did observe diffuse aneurysmal formation of the ascending neoaorta, there were numerous elastic disruptions of elastic laminae with parallel arrangement containing foci of fibrointimal proliferation. The lack of excessive accumulation of myxoid extracellular matrix in this homograft, as reported by Ehsan and associates ${ }^{2}$ in a 14-year-old boy, may be explained by the use of prefixed pericardium as a Norwood patch (in our case) versus pulmonary homograft.

Development of neoaortic valve regurgitation is not uncommon. Under systemic pressure, the structure of pulmonic valves is altered, resulting in worsening incompetence. The pulmonary artery or aortic wall also may be abnormal. The best examples of such dilatation of the aortic or neoaortic root have been observed after either the Ross or Jatene procedure. ${ }^{3}$ We assume dilatation and alteration of the sinotubular junction and root may occur in a similar fashion despite the limited data. ${ }^{4}$ Several molecular mech- anisms have been proposed for aneurysmal dilation from metalloproteinase to alteration in collagen density. ${ }^{5}$

Although there was residual neoaortic valve insufficiency after the downsizing of the valve, further long-term studies are needed to determine the role of the aortic root to prevent future aortic annulus dilatation. We recommend that all patients with a neoaortic valve should undergo close follow-up of the aortic root dimensions, in particular to the annulus and sinotubular junction, as we expect neoaortic aneurysm to be detected in more patients in the near future.

\section{References}

1. Jonas RA, Lang P, Hansen D, Hickey P, Castaneda AR. First-stage palliation of hypoplastic left heart syndrome: the importance of coarctation and shunt size. J Thorac Cardiovasc Surg. 1986;92:6-13.

2. Ehsan A, Singh H, Vargas SO, Sachweh J, Jonas RA. Neoaortic aneurysm after stage I Norwood reconstruction. Ann Thorac Surg. 2005:79:e23-5.

3. Jenkins KJ, Hanley FL, Colan SD, Mayer JE Jr, Castaneda AR, Wernovsky G. Function of the anatomic pulmonary valve in the systemic circulation. Circulation. 1991;84(5 Suppl):III173-9.

4. Cohen MS, Marino BS, McElhinney DB, Robbers-Visser D, van der Woerd W, Gaynor JW, et al. Neo-aortic root dilation and valve regurgitation up to 21 years after staged reconstruction for hypoplastic left heart syndrome. J Am Coll Cardiol. 2003;42:533-40.

5. Segura AM, Luna RE, Horiba K, Stetler-Stevenson WG, McAllister HA $\mathrm{Jr}$, Willerson JT, et al. Immunohistochemistry of matrix metalloproteinases and their inhibitors, inthoracic aortic aneurysms and aortic valves of patients with Marfan's syndrome. Circulation. 1998;98(19 Suppl): III31-7; discussion II337. 

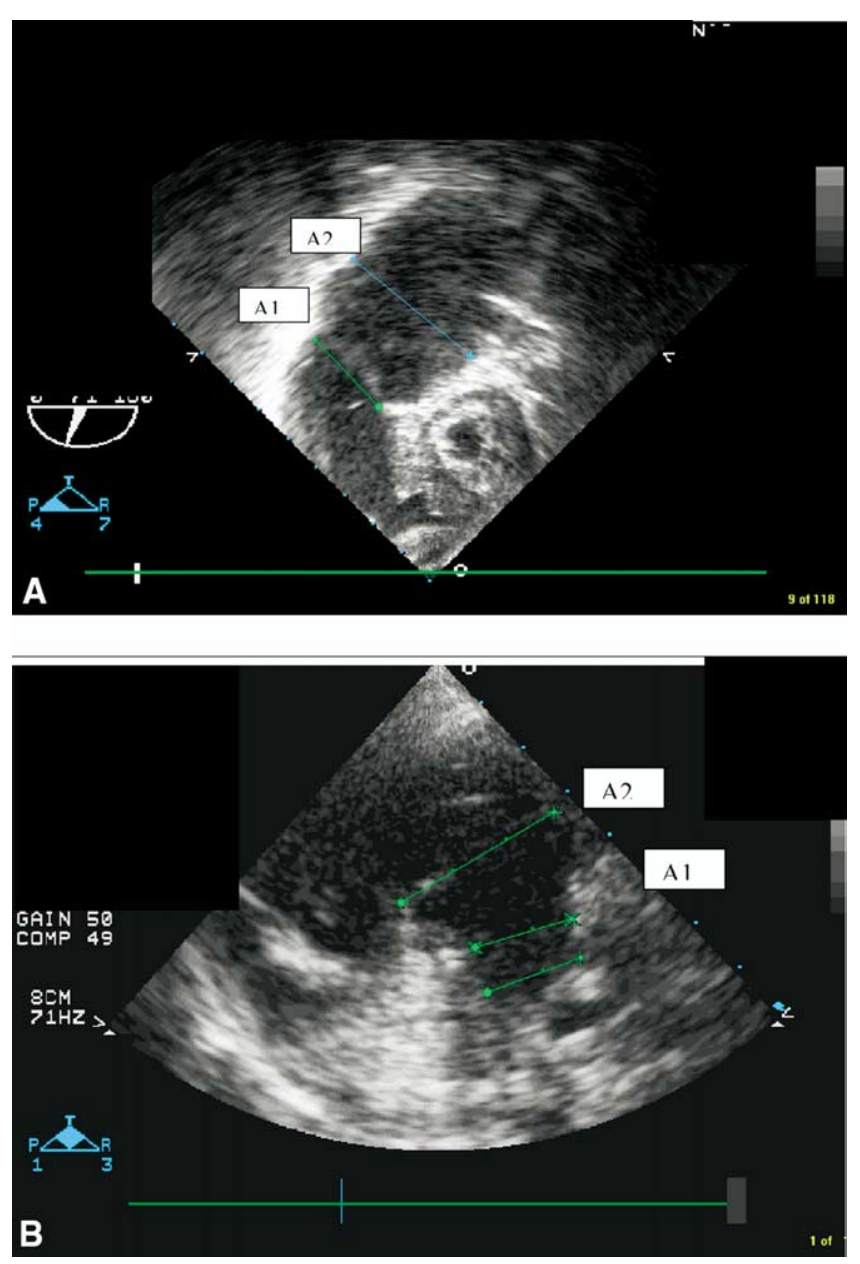

Figure E1. A, Preoperative transesophageal echocardiogram exhibiting preoperative aortic annulus. $A 1$, Preoperative aortic annulus $=28 \mathrm{~mm} ; A 2$, Preoperative sinotubular junction $=38 \mathrm{~mm}$. $B$, Postoperative transthoracic echocardiogram showing a sinotubular junction $17 \mathrm{~mm}$ (A1) and aortic annulus at $24 \mathrm{~mm}$ (A2). 